\title{
UNIVERSIDADES: SURGIMENTO, NACIONALIZAÇÃO E INDICADORES DE INTERNACIONALIZAÇÃO ${ }^{1}$
}

\author{
UNIVERSIDADES: SURGIMIENTO, NACIONALIZACIÓN E INDICADORES DE \\ INTERNACIONALIZACIÓN
}

\author{
UNIVERSITIES: EMERGENCE, NATIONALIZATION AND INDICATORS OF \\ INTERNATIONALIZATION
}

\author{
Iracema Campos CUSATI ${ }^{2}$ \\ Luciano José VIANNA ${ }^{3}$ \\ Paulo César Marques de Andrade SANTOS $^{4}$ \\ Rita di Cássia de Oliveira ANGELO ${ }^{5}$ \\ Antonio Carrillo AVELAR ${ }^{6}$
}

RESUMO: O presente artigo inicia apresentando a trajetória das Universidades desde o surgimento no período medieval, com a criação de uma comunidade de scolares; passando pelo fenômeno da nacionalização, com a consequente perda do seu caráter inicial influenciado pelas escolas de ofício e posteriormente pela ordem eclesiástica e imperial; abordando nesse bojo o processo de estatização a partir da revolução francesa. A universidade brasileira, fortemente influenciada até a década de 1970 pelo modelo europeu, foi impactada pelas premissas das reformas educacionais e objetivos delineados para uma estrutura integradora entre ensino e pesquisa, que ocorreu de forma mais efetiva a partir da década de 1980, movimento apresentado juntamente com as iniciativas de internacionalização da universidade. Por último, são elencadas as estratégias para o desenvolvimento de um projeto de internacionalização das universidades brasileiras no século XXI sob a premissa de que para conceber a cooperação internacional, como parte integrante das missões institucionais, cabe às

1 "O presente trabalho foi realizado com apoio da Coordenação de Aperfeiçoamento de Pessoal de Nível Superior - Brasil (CAPES) - Código de Financiamento 001"

${ }^{2}$ Universidade de Pernambuco (UPE), Petrolina - PE - Brasil. Professora Adjunta do Colegiado de Matemática e Professora Permanente do Programa de Pós-Graduação em Formação de Professores e Práticas Interdisciplinares (PPGFPPI). Doutorado em Educação (USP). ORCID: https://orcid.org/0000-0002-4812-8412. E-mail: iracema.cusati@upe.br

${ }^{3}$ Universidade de Pernambuco (UPE), Petrolina - PE - Brasil. Professor Permanente do Programa de PósGraduação em Formação de Professores e Práticas Interdisciplinares (PPGFPPI). Doutorado em História Medieval pela Universitat Autònoma de Barcelona (UAB). ORCID: https://orcid.org/0000-0001-7355-7609. Email: luciano.vianna@upe.br

${ }^{4}$ Universidade de Pernambuco (UPE), Petrolina - PE - Brasil. Professor Adjunto do Colegiado Pleno de Pedagogia e Coordenador da Linha de Políticas Educacionais, Formação Docente e Práxis Pedagógica do Programa de Pós-Graduação em Formação de Professores e Práticas Interdisciplinares (PPGFPPI). Doutorado em Educação (UFBA). ORCID: https://orcid.org/0000-0001-5803-2388. E-mail: paulo.marques@upe.br

5 Universidade de Pernambuco (UPE), Serra Talhada - PE - Basil. Professora Adjunta no Colegiado de Medicina. Doutorado em Neurociências (UFPE). ORCID: https://orcid.org/0000-0002-1694-1927. E-mail: rita.angelo@upe.br

${ }^{6}$ Universidad Nacional Autónoma de México (UNAM), Cidade do México - México. Professor do Programa de Pós-Graduação em Pedagogia (UNAM), Professor e pesquisador do Programa de Pós-Graduação da Universidad Pedagógica Nacional (UPN) e Professor Visitante do Programa de Pós-Graduação Interdisciplinar em Direitos Humanos (UFG). Pós-doutorado em Educação (USP). ORCID: https://orcid.org/0000-0002-5654-0650. Email: antoniocarrillobr@hotmail.com 
universidades a criação de mecanismos e estruturas apropriadas para promover a internacionalização como um dos pressupostos indicativos desse direcionamento.

PALAVRAS-CHAVE: Internacionalização. Educação superior. Experiências interinstitucionais.

RESUMEN: Este artículo se inicia presentando la trayectoria de las Universidades desde el surgimiento en el periodo medieval, con la creación de una comunidad de escolares; pasando por el fenómeno de la nacionalización, con la consecuente pérdida de su carácter inicial influenciado por las escuelas de oficio y posteriormente por el orden eclesiástica e imperial; abordando en este ámbito el proceso de estatización a partir de la revolución francesa. La universidad brasileña, fuertemente influenciada hasta la década de 1970 por el modelo europeo, ha sido impactada por las premisas de las reformas educacionales y objetivos delineados para una estructura integradora entre enseñanza e investigación, que ocurrió de forma más efectiva a partir de la década de 1980, se presentan juntamente con las iniciativas de internacionalización de la universidad. Por último, se enumeran las estrategias para el desarrollo de un proyecto de internacionalización de las universidades brasileñas en el siglo XXI, bajo la premisa de que para concebir la cooperación internacional, como parte integrante de las misiones institucionales, cabe a las universidades la creación de mecanismos y estructuras apropiadas para promover la internacionalización como uno de los supuestos indicativos de este direccionamiento.

PALABRAS CLAVE: Internacionalización. Educación superior. Experiencias interinstitucionales.

ABSTRACT: This article begins by presenting the trajectory of universities since the emergence in the medieval period, with the creation of a community of students; passing through the phenomenon of nationalization, with the consequent loss of its initial character influenced by the schools of craft and later by the ecclesiastical and imperial order; addressing in this bulge the process of nationalization in from of the French revolution. The Brazilian university, strongly influenced until the 1970s by the European model, was impacted by the premises of the educational reforms and objectives outlined for an integrating structure between teaching and research, which occurred more effectively from the 1980s, are presented together with the initiatives of the university's internationalization. Finally, the strategies for the development of a project for the internationalization of Brazilian universities in the 21st century are listed under the premise that in order to conceive international cooperation, as an integral part of institutional missions, it is up to universities to create appropriate mechanisms and structures to promote internationalization as one of the indicative assumptions of this direction.

KEYWORDS: Internationalization. Higher education. Interinstitutional experiences.

\section{Universidades: do surgimento à nacionalização}

O século XIII foi um momento crucial na história intelectual do Ocidente medieval, principalmente pelo surgimento de uma nova forma de organização social e que serviu para 
romper gradativamente com o pensamento que até então vigorava neste território: as universidades. Dentre as diversas afirmações que podem ser feitas em relação ao surgimento destas instituições no período medieval, algumas são imprescindíveis e devem ser destacadas, como, por exemplo, sua originalidade na sociedade de então, ser um produto do crescimento demográfico da época, promover o favorecimento da promoção de uma sociabilidade e o rompimento de traços até então tradicionais em termos de organização social com a criação de uma comunidade de scolares, ou seja, formada tanto por professores quanto por alunos. $\mathrm{O}$ surgimento das universidades foi um fenômeno de grande importância, em vários sentidos, tanto que Rui Afonso da Costa Nunes (2018, p. 221), em seu livro História da Educação na Idade Média, ao abordar o capítulo sobre as universidades, deixa claro para o leitor que tal capítulo é o "ponto culminante" do seu livro.

Nas palavras de Jacques Verger:

Tornar-se estudante: isso significava, no final da Idade Média, independentemente do estatuto anterior de cada um, aceder a uma condição privilegiada; significava poder furtar-se ao imposto e às formas mais rigorosas da justiça ordinária, significava poder pleitear determinados tipos de proventos (proventos dos benefícios eclesiásticos sem obrigação de residência), significava tomar assento sob a direta salvaguarda das mais altas autoridades, laicas ou eclesiásticas, intervindo indiretamente pelos 'conservadores privilégios' universitários. Antes mesmo de qualquer obtenção de graus, a mera matrícula universitária já era, de uma certa maneira, promoção social (VERGER, 1999, p. 100).

Devemos lembrar que o contexto medieval foi um período em que não havia a ideia de igualdade social perante a lei. Para a época, isso era impensável. Assim, o surgimento da universidade neste período favoreceu a formação de um grupo com condições sociais privilegiadas, de destaque social, um grupo que seria distinto dentro do corpo social medieval e, nas palavras de Le Goff, cada membro deste grupo se sentia "como um artesão, como um homem de ofício" (LE GOFF, 2003, p. 87).

Neste sentido, em termos sociais, aos poucos foi se formando um grupo com uma prática cultural distinta, em diversos termos: ensino com base na utilização de autoridades, uso exclusivo do latim e um procedimento pedagógico essencialmente oral e repetitivo. Ademais, também mantinham uma singular autonomia, com estatutos próprios, regras de cooperação mútua e organização autônoma de suas atividades.

Gradativamente, o campo do saber tornou-se um lócus de formação profissional e destacou na sociedade a figura do intelectual no contexto universitário, como podemos ver nas palavras de Verger sobre a Paris do século XIII: 
Paris tornou-se, verdadeiramente, no século XIII, um foco maior de debate intelectual e de renovação das ideias. Centenas de jovens clérigos foram ali formados nas técnicas mais refinadas do trabalho intelectual, segundo métodos seguros. Evidentemente, este trabalho intelectual comportava regras às vezes rígidas, [...], mas a qualidade do ensino universitário parisiense levou a se fazer progressos decisivos em direção à autonomia, para não se dizer, à profissionalização, da cultura erudita. A figura ainda um pouco vaga das pessoas de saber passou a estar associada a um tipo social bem preciso e excepcionalmente prestigioso, o doutor. Compreender-se que a Universidade de Paris tenha se tornado então um modelo que se procuraria imitar e reproduzir em toda a parte em que se fizesse sentir a aspiração a uma semelhante promoção da cultura (VERGER, 2001, p. 208).

Neste sentido, a importância do século XIII para o Ocidente medieval é destacada com base no surgimento de novos grupos sociais, dentre os quais o universitário, formado tanto por professores quanto por alunos, os quais cada vez mais seriam vinculados como pertencentes a uma cultura identificada como erudita.

Entretanto, embora tenham surgido em espacialidades distantes uma das outras, as universidades medievais destacaram-se desde o início pelo seu caráter internacional, e isso em diversos aspectos. Em primeiro lugar, porque as mesmas favoreceram a migração constante de estudantes entre um território e outro, levando inclusive a formar, no contexto da época, grupos que eram denominados "nações", ou seja, a formação de grupos que estudavam em um território de indivíduos oriundos do mesmo contexto territorial, fato que se refletia no contexto universitário (PEDRERO-SÁNCHEZ, 2000, p. 185). Em segundo lugar, porque muitas vezes os professores também não eram originários do território da universidade, o que implica também em uma movimentação por parte do corpo docente destas instituições (LE GOFF, 2003, p. 101).

Ademais, deve-se destacar também a utilização da língua latina nas aulas, a qual foi utilizada para fazer veicular as informações referente aos estudos, principalmente em um contexto no qual as línguas vulgares estavam cada vez mais se destacando (VERGER, 2002, p. 580). Neste sentido, a formação da universidade medieval já apresenta uma característica que vemos hoje nas universidades atuais, e, dessa forma, sua formação pode ser caracterizada como dinâmica em termos sociais.

A criação das universidades obedeceu basicamente a dois contextos. Um primeiro, chamado ex-consuetudine, referia-se à junção a partir de centros de estudos já existentes anteriormente, geralmente formados pela reunião de professores. Neste caso, as universidades eram organismos autônomos de natureza de caráter corporativo, eram reconhecidas pelas instituições eclesiásticas e laicas e tinham autonomia em relação ao ensino, aos programas das 
disciplinas, à duração dos estudos, modalidades de exames, entre outros (VERGER, 1999, p. 82). É necessário destacar que este modelo de formação universitária correspondia a um desejo de organização autônoma de uma comunidade de mestres e estudantes, apresentandose como outro ofício urbano qualquer (BASCHET, 2006, p. 214). O segundo contexto, surgido posteriormente, chamado ex-privilegio, era uma criação universitária concedida pelo poder estatal (NUNES, 2018, p. 230). Assim, com o passar dos séculos, cada vez mais ocorreu a associação entre o mundo universitário e outro fenômeno que estava se formando neste mesmo contexto: a formação estatal.

Em termos de formação do estado durante o Medievo, o século XIII apresenta o que seria o quarto estágio da formação estatal de acordo com Genet, aquele que seria, inclusive, o anterior ao estado absolutista. Cada vez mais havia uma centralização de poder, a criação de grupos burocráticos, uma padronização das cobranças de impostos em relação à sociedade e uma padronização em termos de relação da sociedade com o rei, na figura do súdito (GENET, 2002, p. 405-408). Afonso X, rei de Castela entre os anos 1252 e 1284, conhecido como o Sábio pelo seu envolvimento com atividades intelectuais no século XIII, nos apresenta esta divisão:

Um estudo é uma associação de mestres e de escolares feita num determinado lugar com a vontade e a intenção de aprender os saberes. E dele existem duas modalidades: uma é a que chamam "estudo geral", onde há mestres das artes, assim como de gramática, de lógica, de retórica, de aritmética, de geometria, e de astrologia, e outrossim em que há mestres de decretos e senhores de leis (mestres de direito civil); este estudo deve ser estabelecido por mandado de papa, de imperador ou de rei. A segunda modalidade é a que chamam "estudo particular", quer dizer, quando um mestre ensina nalguma cidade, apartadamente, a poucos escolares. E este, pode mandá-lo fazer o prelado ou conselho de qualquer lugar (PEDREROSÁNCHEZ, 2000, p. 182).

O primeiro exemplo apresentado no fragmento acima, que na verdade surgiu depois do segundo, é o momento no qual a universidade passa a ser um assunto político, vinculado a uma iniciativa de criação política. Dessa forma, a associação dos termos intelecto - poder foi um fenômeno que envolveu o contexto universitário cada vez mais a partir do século XIV, integrando-se à dinâmica estatal de cada território. Se em um primeiro momento as universidades foram criadas a partir de uma criação já anterior (ex-consuetudine), posteriormente, cada vez mais as mesmas foram incorporadas ao contexto estatal (exprivilegio), e foram utilizadas como instrumentos para fortalecer o poder dos estados então nascentes e cada vez mais burocráticos no final do período medieval. Cada vez mais, portanto, 
iniciou-se um fenômeno que conhecemos como a nacionalização das universidades, cujo primeiro exemplo foi Praga (LE GOFF, 2003, p. 177-178).

Uma das primeiras consequências desta nacionalização foi a perda do seu caráter internacional, onde aspectos nacionais ou até mesmo regionais assumiram um destaque em comparação com aspectos internacionais, onde a iniciativa da criação está a cargo de soberanos e de papas. Dentre as universidades deste calado, podem ser citadas, por exemplo: Salamanca, entre 1220 e 1230; Lisboa (1290); Coimbra (1290); Lérida (1300); Praga (1347); Perpignan (1350); Huesca (1354); Colônia (1388); Barcelona (1450); Friburgo-em-Brisgau (1455-1456); Basileia (1459), entre outras (LE GOFF, 2003, p. 169-170).

A iniciativa real em relação à fundação das universidades estava vinculada a questões políticas do território, tais como o seu próprio desenvolvimento, o benefício favorecido aos súditos e a tentativa de evitar a participação de políticos estrangeiros (NUNES, 2018, p. 231). Porém, se o século XIII foi o século de ouro das universidades com a constituição das mais importantes, como Paris, Salamanca e Oxford (NUNES, 2018, p. 231), nos séculos seguintes elas começaram a perder as suas características iniciais, ou seja, perda da autonomia inicial em detrimento da centralização feita pelo Estado, e a perda do caráter internacional com a criação de diversas outras universidades em diversos territórios (NUNES, 2018, p. 250). E foi justamente neste contexto que as universidades começaram a estabelecer cada vez mais uma relação de poder com o Estado da época, como podemos observar nas palavras de Le Goff:

No final da Idade Média as grandes universidades se convertem em potências políticas, desempenham um papel ativo, às vezes de primeiro plano, nas lutas entre os estados, são o teatro de violência e crise que opõem as 'nações' inspiradas a partir de então por um sentimento nacional e se integram, por fim, nas novas estruturas nacionais dos estados (LE GOFF, 2003, p. 132).

Em termos gerais, pode-se afirmar que a partir do século XIV cada vez mais as universidades se direcionaram para ser um importante instrumento de poder por parte do papado e das monarquias, com a formação de profissionais para atuarem no âmbito do poder na origem do Estado laico na Baixa Idade Média. Sua autonomia inicial foi gradativamente sendo englobada pelos Estados que estavam surgindo, e cada vez mais passaram a ser instrumentos nacionais dos novos territórios em formação. Entretanto, dois fenômenos em relação ao mundo universitário, que surgiram no contexto medieval, iriam continuar nos séculos seguintes: a migração de estudantes e a expansão das universidades. 


\section{A migração de estudantes e a expansão da universidade}

A migração de estudantes é um fenômeno iniciado com as primeiras escolas filosóficas do século III (A.C), como a Hekadimia de Platão na cidade de Atenas. Embora sem essas mesmas características, a academia universitária da idade média contou como marco importante para o desenvolvimento das instituições universitárias a migração de estudantes e professores. Conhecidas no século XII por Studium Generale (Estudos Gerais), essas instituições tinham como objetivo, além de formar clérigos para defesa da fé católica, contribuir para formação dos filhos dos nobres. Com o passar dos anos os Studium Generale passaram a ser chamados de Universitas Studii ou Magistrorum et Scolarium.

Para Jaques Verger (1990), a palavra Studium significava lugar onde os alunos estudavam, um tipo de estabelecimento de Ensino Superior onde se reuniam os aprendizes e mestres. E universitas o nome da organização corporativa responsável pela manutenção e administração do studium. Para a legislação em vigor, significava qualquer tipo de comunidade ou corporação.

Provavelmente, as primeiras relações didáticas estabelecidas nesses tipos de associações tenham sido semelhantes às das corporações de ofício onde eram comuns o compartilhamento dos conhecimentos técnicos, profissionais e a prática de atividades de manutenção e proteção da corporação. Pela necessidade de uma sistematização dos conteúdos trabalhados nasce o currículo como instrumento que produz a formação esperada pela sociedade.

O currículo era composto por atividades instrumentais e práticas oriundas do college. As atividades instrumentais eram compostas pelo conjunto de três (triviun) ramos do conhecimento (disciplinas): gramática, retórica e dialética. $\mathrm{E}$ as atividades práticas de quatro (cuandriviu) ramos do conhecimento (disciplinas): Astronomia, Geometria, Aritmética e Música. No exercício comum e diário dessas corporações, os alunos eram conduzidos ao exercício de uma "mentalidade laica, técnica e racionalista" (CAMBI, 1999, p. 174-175).

Até meados do século XIV as universidades e faculdades funcionavam em casas alugadas, conventos e igrejas. Por vezes, nos conflitos com as autoridades locais, os professores e alunos ameaçavam migrar para outra região. A partir do final do século XIV, a Universidade de Paris começou a fixar o seu funcionamento com a aquisição de prédios e edifícios. No século XV, o mesmo passou a ocorrer com outras universidades. 
Por volta de 1500 , tanto as novas universidades como as velhas possuíam edifícios acadêmicos apropriados - salas de aulas, salas de reuniões, uma capela, uma ou mais bibliotecas, alojamentos para estudantes e professores. [...] agora, as universidades já não podiam ameaçar com a migração, nem as autoridades tolerar greves ou secessões (GIEYSZTOR, 2000, p. 135-138).

Por volta dos anos 1500, em quase todas as regiões da Europa já havia uma Universidade; como os currículos eram semelhantes, era muito comum estudantes migrarem de uma região para outra, por exemplo, saírem da Universidade de Coimbra em Portugal para estudarem em Oxford na Inglaterra ou o estudante sair de Salamanca, na Espanha, para estudar em Toulouse, na França. Por conta das distâncias, mesmo entre regiões contíguas como Espanha e França, os estudantes se deslocavam de uma para outra com a finalidade de ali permanecerem. Os mais afortunados eram mantidos a expensas de suas famílias e os menos afortunados trabalhavam para custear seus estudos. Essas migrações eram comuns e constantes em todo o período medieval.

Segundo Santos (2014, p. 90), com o passar do tempo, as cidades onde essas Universidades foram estabelecidas passaram a ser conhecidas como cidades universitárias, que se beneficiavam tanto com a mobilidade quanto com a migração de estudantes. A migração e a mobilidade eram estimuladas por dois fatores: as aulas nas universidades eram em latim e os graus eram os mesmos em todas as universidades. Um estudante geralmente iniciava seus estudos em uma universidade perto de sua residência e poderia concluí-los em outra mais distante.

No fim da Idade Média a Europa já contava com 60 universidades estruturadas nas denominadas cidades universitárias. Com o Renascimento, esse número cresceu rapidamente, chegando a 143 em 1790. Mas, apesar do aumento no número de instituições, isso não impediu que as grandes cidades e capitais como Londres, Amsterdam, Anvers, Bruxelas, Rouem, Lyon, Madrid, Milan, Berlin, Saint-Pétersbourg perdessem o controle político e financeiro sobre elas (CHARLE; VERGER, 2012, p. 48).

Com as grandes navegações, os hispânicos levaram para suas colônias o modelo de educação superior europeia. Entre os anos de 1511 a 1609, foram criadas nas colônias espanholas 16 universidades. Entre 1677 e 1791, muitas dessas universidades serviram de cenários para criação de outras e extinção de outras tantas.

Nesse mesmo período, surgem as primeiras universidades fora da Europa, principalmente nas colônias da América do Norte e na América Latina. Em paralelo a esse movimento expansionista surge um novo modelo de universidade, com uma estrutura administrativa diferente, concepção de ensino, tipologia e metodologias diferentes da 
desenvolvida no período medieval, mas adaptada à ideologia dominante dos grupos que deram origem a essas instituições.

Um dos fatores marcantes na vida dos estudantes migrantes é que quando se tornam egressos das universidades estrangeiras, uma grande parte não retorna mais para os países de origem, sendo inseridos no mercado de trabalho do país de destino. O que não acontece na grande maioria dos estudantes em mobilidade acadêmica internacional:

No início do século XIV, havia 301 médicos registrados em França; destes, $57,8 \%$ tinham estudado em Paris, 35,2\% em Montpelllier, 2,7\% noutras faculdades de medicina francesas e $4,3 \%$ no estrangeiro. No final do século $\mathrm{XV}$, num total de 436 médicos, os alumni de Montpellier formavam apenas $16,3 \%$ do total e os de Paris 47,5\%; outras universidades de França, então, $27,6 \%$ e as faculdades estrangeiras 8,5\%. Paris - e Montpellier ainda mais perderam terreno para Caen, Toulose e Avanhão, ou para Perpinhão, Cahors, Angers, Dôle, Nantes, Poitiers, Bordéus e Borges. Os diplomados pelas universidades estrangeiras eram quase todos estrangeiros que, depois de terem terminado os seus estudos, vinham exercer a profissão na França (RIDDER-SYMOENS, 1996, p. 286).

A reforma protestante impactou positivamente na expansão do número de instituições de Ensino Superior dentro e fora da Europa. Além das criadas pelo Estado e pela Igreja Católica, contava-se agora com as Luteranas e Calvinistas, influenciando diretamente na redução do fluxo migratório dos estudantes. A redução desse fluxo foi possibilitada graças à expansão no número de instituições de ensino.

\section{Estatização das universidades}

Nos 300 anos que separam o processo de declínio do medievo e a estabilidade do estado moderno (século XV a XVIII), a universidade alcança o absolutismo monárquico, regime político pelo qual reunia ao mesmo tempo e região monarcas, nobres e burgueses e que favoreceu o desenvolvimento das instituições públicas mantidas administrativamente por um corpo burocrático.

Com o advento da revolução francesa de 1789, onde Napoleão Bonaparte, sob a égide da monarquia constitucional, assumiu o completo controle estatal e submeteu o Estado Francês a uma profunda reforma institucional e administrativa, entre elas a do ensino, a Universidade de então passou por profundas modificações, adquirindo características das quais algumas delas estão presentes nas universidades atuais.

Vista como uma instituição perigosa pelos revolucionários franceses por manter as tradições do velho regime medieval, cujo currículo, embasado na cultura clássica, impedia a 
divulgação e o ensino, portanto, a assimilação de novos conhecimentos produzidos pelas ciências experimentais e pelo enciclopedismo. Em 1806, com o apoio da assembleia constituinte, foi aprovada a lei que passou a disciplinar o ensino superior em toda a França: "Ela será formada, sob o nome de Université Imperiale, uma corporação encarregada exclusivamente do ensino e da educação pública em todo Império."

A universidade, além de se tornar uma instituição pública, pertencente ao monopólio estatal, laica por conta dos princípios revolucionários e agora cartorial por conta das certificações, graus e diplomas, passou a disciplinar o funcionamento e a estrutura didáticopedagógica das faculdades existentes, as escolas primárias, os colégios, os Liceus e qualquer outra instituição de ensino.

Em suma, a universidade era vista como um aparelho ideológico do Ancien Régime. Sucessivos decretos revolucionários, aos quais se juntou o decreto napoleônico de março de 1808, produziram profundas mudanças no panorama do ensino superior. Foram criadas as Escolas Politécnicas, a Faculdade de Ciências e a Faculdade de Letras; e as Escolas de Medicina e de Direito foram promovidas a Faculdades (CUNHA, 2007, p. 16-17).

Semelhante à relação dos governantes para com a sociedade civil da época, a universidade, revestida da burocracia estatal, passou a agir de forma autoritária e ditar regras para seu corpo docente e discente, que não tinham clareza da situação, porque a educação não estimulava a crítica, pelo contrário, servia como doutrinação, mantendo os interesses do governo e da elite burguesa.

$\mathrm{Na}$ esteira do Iluminismo, outros países europeus passaram a refletir sobre a importância do papel social da universidade. Destaca-se a Alemanha que, influenciada por pensadores como Wilhelm Von Humboldt e filósofos iluministas, estatizou o ensino superior a partir do entendimento de que a Universidade é uma instituição vital para a manutenção e reprodução da identidade nacional.

Se destaca na produção desses filósofos as de Wilhelm Von Humboldt (1767-1835), considerado por muitos autores como pai da universidade moderna, ao introduzir na pedagogia universitária a indissociabilidade entre ensino e pesquisa nas práticas formativas fundamentadas no desenvolvimento científico. Para Humboldt, o chão da universidade é o território apropriado para o enlace entre a ciência e a política, entre o desenvolvimento do espírito crítico e da ação prática: “[...] a universidade mantém sempre uma relação intrínseca com a vida prática e com as necessidades do Estado, já que, ao orientar a juventude, desempenha tarefas pragmáticas que interessam ao Estado" (HUMBOLDT, 1997, p. 94-95). 
Segundo Fallon (1983), a universidade se tornava parte do Estado não apenas para unificar culturalmente a nação, mas, simultaneamente, para humanizar o Estado, cabendo a este a obrigação de manter a dinâmica do desenvolvimento científico apresentado pela universidade.

Brunner (2014) destaca duas vertentes distintas no processo de estatização da universidade: a vertente francesa e a vertente alemã. Para ele:

a vertente alemã, idealista-romântica, dá ao modelo de universidade pública ocidental uma elevada autoconsciência como parte integrante do Estado e expressão cultural da nação. Por outro lado, a vertente francesa, mais político-administrativa, concede a legitimidade e o reconhecimento como um serviço público de primeira ordem, como formadora das elites nacionais (BRUNNER, 2014, p. 15-16).

A vertente alemã pensa a universidade como um espaço de fortalecimento das representações culturais, valorização da identidade, humanização das relações nos contextos sociais, políticos e econômicos. A vertente francesa, por outro lado, pensa a universidade como instituição formadora das elites, mesmo tendo como lema político institucional a liberté, égalité e fraternité.

\section{Estratégias de internacionalização das universidades brasileiras}

A educação superior no Brasil vem se internacionalizando progressivamente, tendo como marco inicial as propositivas das reformas educacionais das décadas de 1960 e 1970, que enfocavam a necessidade de uma estrutura educacional mais integradora, propiciando unidade entre ensino e pesquisa.

A partir da década de 1980, as iniciativas de internacionalização da universidade brasileira se concretizaram contemplando alguns dos objetivos mencionados no artigo $15^{\circ}$ da Declaração Mundial sobre Educação Superior no Século XXI: Visão e Ação, entre eles, o "compartilhamento de conhecimentos teóricos e práticos entre países e continentes"7. A declaração é enfática ao conceber que as instituições de Ensino Superior devem, dentre outras funções, assumir a iniciativa de internacionalização e não somente reagir diante das demandas da globalização.

A internacionalização consubstancia a valorização e o respeito pelas diferenças e pela identidade. O efeito da internacionalização é explicitado num conjunto de esforços

7 Disponível em: http://www.direitoshumanos.usp.br/index.php/Direito-a-Educação/declaracao-mundialsobreeducacao-superior-no-seculo-XXI-visao-e-acao.html. Acesso em: 2 jan. 2021. 
institucionais envidados para se adaptar a um mundo globalizado, que tem no processo de globalização a universalização de estratégias eficazes e eficientes em prol do pleno conhecimento.

Globalização significa inclusão, conexões entre grupos, regiões etc. Também significa exclusão pois, enquanto grupo e regiões estão conectados, outros tantos e tantas estão excluídos. Nesse sentido, globalização e guetorização - inclusão e exclusão - se tornam aspectos do mesmo processo (VERWOERD, 1954).

Da exposição sucinta das matrizes iniciais, desencadeia a premissa de que para conceber a cooperação internacional como parte integrante das missões institucionais, cabe às universidades a criação de mecanismos e estruturas apropriadas para promover a internacionalização como um dos objetivos indicativos desse direcionamento.

As instituições de ensino superior precisam se moldar a este novo cenário mundial para que possam se equiparar aos países desenvolvidos, pois um cenário globalizado, e cada vez mais competitivo, a integração passa pela internacionalização e pela capacidade de inovar.

O processo de internacionalização das instituições de ensino superior no Brasil ocorre de formas diversas, tendo em vista a autonomia de cada Universidade. No entanto, o modo mais comum se dá pela cooperação internacional, que inclui a mobilidade de acadêmicos, gestores e professores. Relevante ressaltar que a internacionalização não ocorre isoladamente, pois pressupõe cooperação em todas suas formas, sejam acadêmicas, científicas e tecnológicas, e em seus diferentes níveis, desde que voltadas ao âmbito da cooperação interinstitucional (STALLIVIERI, 2001).

A internacionalização das instituições de ensino superior em suas diferentes formas de cooperação tem se tornado essencial para a melhoria da qualidade do ensino e da pesquisa que, articulados, criam as condições para o desenvolvimento dos países participantes e promovem melhor qualidade de vida das populações.

As universidades públicas na América Latina, no contexto da globalização, estão sujeitas a forças e tensões, que derivam em políticas públicas, pela necessidade de gerar propostas para enfrentamento dos desafios atuais de formação, buscando consolidar ações que atendam às demandas educacionais do mundo globalizado. Neste cenário, uma das mais complexas estratégias educacionais e políticas que as instituições de ensino superior têm de enfrentar refere-se à internacionalização como aponta Didriksson (2015), visto que existe uma política de interdependência econômica, social e cultural, facilitada recentemente pela mídia de informação e comunicação. 
A internacionalização acadêmica, durante a última década, vem se fortalecendo na rotina da vida universitária e, por ser uma situação relativamente nova para muitas instituições do ensino superior latinoamericano, são apresentadas na sequência estratégias metodológicas de uma experiência com ações de intercâmbio em desenvolvimento pelos autores deste artigo, por entendermos que é urgente promover uma reflexão sobre a concepção de internacionalização assumida nas instituições de ensino superior. $\mathrm{O}$ intuito é dar visibilidade aos conceitos que permeiam a cooperação internacional em nível acadêmico e as formas em que ela se configura e se concretiza, destacando os desafios para a efetiva internacionalização institucional, tendo como foco a realidade das instituições de ensino superior.

\section{A experiência interinstitucional de internacionalização}

Com o objetivo de compreender, vis-a-vis relatos de experiências de estudantes intercambistas, as teorias que fundamentam a abordagem didática de um projeto de articulação interinstitucional como prática de internacionalização binacional, serão explicitados os desafios e as possibilidades de mudanças na prática educativa, possibilitados pelo diálogo do conhecimento e de cosmovisões dos povos indígenas em relação às demandas contemporâneas da vida intercultural. Vale dizer que a formação de professores em contextos interculturais de internacionalização é fortemente permeada por crenças, compromissos sociais e culturais distintos, conduzindo a reflexões e avaliações de ricas experiências acadêmicas derivadas de práticas de mobilidade, currículos, viagens, diferentes idiomas e experiências em propostas dita inovadoras.

A proposta metodológica em desenvolvimento com estudantes intercambistas parte de uma noção ampla de flexibilidade curricular (PARASKEVA, 2011), que a considera como um processo coletivo e individual de criação e recriação das formas de reorganização, percepção e interpretação do currículo presumido como um processo de comunicação e interação entre diferentes espaços curriculares. A flexibilidade é vista na organização horizontal e vertical, na elaboração de produtos acadêmicos e na maneira pela qual eles são concebidos e utilizados com originalidade e harmonizados com contextos reais.

Baseando-se nos princípios de uma filosofia da internacionalização e para uma melhor compreensão do programa e de suas práticas de internacionalização, são elencadas premissas da parceria entre instituições de ensino superior no Brasil e no México que, apoiadas numa ampla flexibilização curricular, consideram um processo coletivo e individual de criação e recriação como forma de reorganização, percepção e interpretação do currículo, reconhecendo 
que se os programas de mestrado têm a tarefa principal de produzir e criar conhecimento significa que devem aceitar a diversidade acadêmica.

Os objetivos dessa experiência de internacionalização são, entre outros: propor elementos acadêmicos concretos para envolver estudantes de pós-graduação e professores em uma experiência alternativa de formação entre as instituições parceiras; identificar problemas acadêmicos muito específicos que possam ser articulados aos projetos de pesquisa; estabelecer diretrizes de trabalho e implementação de internacionalização que contribuam para favorecer uma estratégia de articulação dentro das linhas acadêmicas que compõem os programas de pós-graduação; potencializar as condições acadêmicas e materiais existentes nos programas de pós-graduação para possibilitar um maior processo de internacionalização e explorar elementos específicos de logística dentro das instituições para promover práticas de internacionalização.

Portanto, após esse preâmbulo, passamos à apresentação do projeto (AVELAR; ROA; CUSATI, 2019, p. 1195-1201), elencando estratégias de seu desenvolvimento e de seu sentido pedagógico:

I) A utilização das narrativas das experiências dos alunos no programa de internacionalização é a primeira documentação (registro escrito) utilizada para explorar em profundidade as ideias sobre a experiência de mobilidade acadêmica e buscar o potencial de mudança em outros cenários educativos.

II) As experiências relatadas relacionadas aos vínculos interculturais entre o Brasil e o México tem como propósito apresentar depoimentos, em forma de seminários, nos quais os estudantes vivenciam a experiência de internacionalização na comunicação em diferentes idiomas. Embora os entusiasmos possam ser percebidos na experiência vivida e retratados nos relatos, é perceptível o progresso alcançado pelo compartilhamento de aspectos socioculturais e linguísticos dos países dos participantes.

III) O compromisso social dos estudantes com seu povo, sua comunidade de origem, compromisso que vai além da conclusão de estudos de pós-graduação de natureza acadêmica, pois são enumerados outros relacionados à consciência de suas responsabilidades e o vínculo com obrigações sociais.

IV) Experiência que acumula conhecimentos, sentimentos, valores e ações que ampliam a compreensão dos direitos humanos pelas experiências interculturais. 
V) Experiências acadêmicas formais são possibilitadas pelos seminários de aprofundamento teórico-metodológico que subsidiam as pesquisas e propiciam o progresso das mesmas, pois há ênfase no rigor da pesquisa acadêmica e de sua escrita.

VI) Experiências de intercâmbios culturais promovem o estudo e o fortalecimento de práticas culturais em programas de pós-graduação para estudantes de diferentes nacionalidades. Nesta atividade de troca de experiências culturais são valorizados, entre outros, os costumes, o vestuário, a organização social e as manifestações artísticas que permitam compreender as estruturas culturais internas que os estudantes possuem e favorecer um entendimento integral das vivências acadêmicas que são construídas nesse processo de práticas com variados traços culturais.

O trabalho de intercâmbio compartilhado favorece o desenvolvimento de uma identidade individual e coletiva pois, além das pesquisas individuais, ofício de cada pósgraduando, há experiências de pesquisas em equipe e vivências de pesquisadores em formação com pesquisadores acadêmicos reconhecidos pela sua produção.

Vínculos binacionais favorecem a geração e a aplicação do conhecimento dos estudantes que irão expandir e revitalizar, com o apoio teórico, os resultados de suas investigações específicas.

É premente a necessidade de se avançar na construção de elementos norteadores da internacionalização da educação superior no marco dos instrumentos de política pública, o que exige uma revisão da própria política externa brasileira, enfatizando mais os temas educativos e científicos, assim como promovendo a abertura de oportunidades no âmbito educacional. Da mesma forma, é demandada da instituição de ensino superior uma revisão das limitações estruturais que enfrenta o seu sistema em relação à internacionalização, para que se possa definir fórmulas para o avanço nesse processo.

\section{REFERÊNCIAS}

AFONSO X, O SÁBIO. Las Siete Partidas. In: PEDRERO-SÁNCHEZ, Maria Guadalupe. História da Idade Média. Textos e Testemunhas. São Paulo: Editora Unesp, 2000.

AVELAR, Antonio Carrillo; ROA, Andrea Olmos; CUSATI, Iracema Campos. Articulações entre educação intercultural e práticas de internacionalização entre México e Brasil. Revista Ibero-Americana de Estudos em Educação, Araraquara, v. 14, n. 3, p. 1182-1204, jul./set. 2019. e-ISSN: 1982-5587. DOI: https://doi.org/10.21723/riaee.v14i3.12486 
BASCHET, Jérôme. A civilização feudal. Do ano mil à colonização da América. Rio de Janeiro: Globo, 2006.

BRUNNER. J. J. Ensaio: aval. pol. públ. Educ., Rio de Janeiro, v. 22, n. 82, p. 11-30, jan./mar. 2014.

CASTAÑEDA, José Antonio Serrano. Alrededor de la idea de formación. In: SALINAS, Sonia Comboni (Coord.). La investigación educativa en México. México: COMIE-UPN, 2001.

CHARLE, Christophe; VERGER, Jacques. Histoire des universités. Paris: Presses Universitaires de France, 1994.

DIDRIKSSON, Axel. La universidad de la innovación. México: CESU/UNAM, 2015.

FALLON, Daniel. The German University: a heroic ideal in conflict with the modern world. Boulder, Colorado: Colorado Associated University Press, 1983.

GENET, Jean-Philippe. Estado. In: Dicionário Temático do Ocidente Medieval. São Paulo: Edusc, 2002. v. 1. p. 397-409.

HUMBOLDT, Wilhelm von. Sobre a organização interna e externa das instituições científicas superiores em Berliml. Rio de Janeiro: EdUERJ, 1997.

LE GOFF, Jacques. Os intelectuais na Idade Média. Rio de Janeiro: José Olympio editora, 2003.

LUCAS-DUBRETON, Jean. La France de Napoléon. Paris: Librairie Jules Tallandier, 1981.

NUNES, Rui Afonso da Costa. História da educação na Idade Média. Campinas: Kirion, 2018.

PARASKEVA, João. Nova teoria curricular. Portugal: Edições Pedago, Lda, 2011.

SANTOS, Paulo César Marques de Andrade. Politiques publiques de mobilité académique internationale: une étude exploratoire du quotidien d'étudiants brésiliens dansla ville de Lyon - France. Orientadores: Dra. Rosilda Arruda Ferreira, Bahia - Brasil; Dr. Jean-Claude Régnier - Lyon2, Lyon - França. 2014. 342 f. Tese (Doutorado em Educação) - Faculdade de Educação, Universidade Federal da Bahia; Faculté Sciences de l'Education, Ecole Doctorale Education, Psychologie, Information et Communication, Université Lumière-Lyon 2. Disponível em: https://repositorio.ufba.br/ri/bitstream/ri/18687/1/TESE\%20\%20Mobilidade\%20Acad\%C3\%AAmica\%20Internacional.pdf. Acesso em: 24 fev. 2020.

STALLIVIERI, Luciane. Guia de Orientações para Alunos e Professores Participantes de Programas de Intercâmbios Internacionais. Caxias do Sul: Gráfica da UCS, 2001.

VERGER, Jacques. Cultura, ensino e sociedade no ocidente nos séculos XII e XIII. Bauru: EDUSC, 2001.

VERGER, Jacques. Homens e saber na Idade Média. Bauru: EDUSC, 1999. 
VERGER, Jacques. Universidade. In: Dicionário Temático do Ocidente Medieval. São Paulo: EDUSC, 2002. v. 2. p. 573-587.

VERWOERD, Hendrik Frensch. Bantoe-onderwys: Beleidsbepaling vir die onmiddelike toekoms. Verklaring. Deur dr H.F. Verwoerd, Minister van Naturellesake, in die Senaat van die Parlement van die Unie van Suid-Afrika, 7 jun. 1954. Pretoria: Staatsdrukker.

\section{Como referenciar este artigo}

CUSATI, I. C.; VIANNA, L. J.; SANTOS, P. C. M. A.; ANGELO, R. C. O.; AVELAR, A. C. Universidades: surgimento, nacionalização e indicadores de internacionalização. Revista Ibero-Americana de Estudos em Educação, Araraquara, v. 16, n. 1, p. 3-19, jan./mar. 2021. e-ISSN: 1982-5587. DOI: https://doi.org/10.21723/riaee.v16i1.13354

Submetido em: 20/02/2020

Revisões requeridas: 06/03/2020

Aprovado em: 30/09/2020

Publicado em: 02/01/2021 